\title{
Effects of Di-Ethyl-Ether Addition on the Water-Diesel Emulsion Fuel Combustion Pressures and Pressure Rise Rates
}

\author{
Mohamed Y. E. Selim ${ }^{1, ~ *, ~ M a m d o u h ~ T . ~ G h a n n a m ², ~ A d e l ~ M M ~ H u s s i e n ~}{ }^{3}$ \\ ${ }^{1}$ Mechanical Eng. Department, College of Engineering, UAE University, Al-Ain, UAE \\ ${ }^{2}$ Chem. and Pet Eng. Department, College of Engineering, UAE University, Al-Ain, UAE \\ ${ }^{3}$ Mech Power Eng. Department, Faculty of Engineering, University of Helwan, Cairo, Egypt
}

Email address:

mohamed.selim@uaeu.ac.ae (M. Y. E. Selim)

${ }^{*}$ Corresponding author

\section{To cite this article:}

Mohamed Y. E. Selim, Mamdouh T. Ghannam, Adel MM Hussien. Effects of Di-Ethyl-Ether Addition on the Water-Diesel Emulsion Fuel Combustion Pressures and Pressure Rise Rates. American Journal of Modern Energy. Vol. 3, No. 6, 2017, pp. $146-152$.

doi: $10.11648 /$ j.ajme.20170306.15

Received: October 16, 2017; Accepted: October 31, 2017; Published: December 26, 2017

\begin{abstract}
An experimental investigation has been carried out to investigate the effects of adding very low viscosity renewable fuel of Di-Ethyl Ether (DEE) to a 30\% water-in-diesel emulsion on the diesel engine combustion characteristics. A research engine of Ricardo E-6 has been used throughout the work and the water-diesel emulsion (W/D emulsion) has been prepared to have four weeks of fuel stability. The W/D emulsion then mixed with the low viscosity additive to reduce the viscosity of the W/D emulsion. Diesel engine combustion pressure and other engine parameters, have been collected by dataacquisition systems and the maximum pressure rise rate has been calculated. It has been found that adding the DEE to the W/D emulsion affected its viscosity and affected the combustion as noticed from the combustion pressures and pressure rise rates. Using an additive like the DEE enables the use of W/D emulsion in diesel engine with high amount of water of $30 \%$ with acceptable combustion characteristics.
\end{abstract}

Keywords: Diesel Engine, Water-Diesel Emulsion, Combustion Pressure, Engine Roughness, Di-Ethyl-Ether

\section{Introduction}

Due to high thermal performance and fuel consumption economy, diesel engines have several important applications in our modern technologies. Diesel engines are widely utilized as a source of power for many industrial and civilian activities. Some of these applications are power plants, hospitals, marine-, land-, and rail-transportations. But, the diesel engines emissions usually cause a serious negative effects on the air quality. The diesel engines exhaust contains nitrogen oxides, particulate matters, black smoke, carbon mono-oxide, and carbon-dioxide. The results of these materials in our environment will lead to serious damage to the atmosphere such as destruction of the ozone layer, acid rains, and green-house effects [1]. Due to the recent environmental policies, the decrease of the negative effects of diesel engines gas emissions is important. For example, the emission of particulate matters and $\mathrm{NO}_{\mathrm{x}}$ usually lead to serious problems in the large city environments where traffic congestion is very heavy. Many researchers have reported that the water addition into the diesel fuel to produce waterin-diesel fuel emulsion significantly reduces the pollution level of particulate matters and $\mathrm{NO}_{\mathrm{x}}$ [2-4].

The addition of water in a dispersed droplets phase into a continuous diesel fuel phase will result to the formation of water-in-diesel emulsion (W/D emulsion). In general, there are several important industrial and environmental applications for water-in-oil emulsions. Some examples are: oil spill [5] and transportation of heavy crude oil in water emulsion through pipeline [6]. Some other examples that involve stable emulsions are food industries (e.g. mayonnaise), pharmaceutical industries (e.g. drug emulsions) and cosmetics industries (e.g. skin lotion). In the preparation 
of W/D emulsion, the addition of surface active agent is very necessary to stabilize the W/D emulsion. There are two roles for the effect of the surface active agent within the W/D emulsion. The first role for the surface active material is to decrease the interfacial tension between the water phase and the diesel fuel phase in order to help the formation of W/D emulsion. The second role is to stabilize the water droplets phase within the diesel fuel phase to prevent the coalescence of the water phase [7]. Surface active material accumulates at the interfacial film between the water droplets phase and the diesel fuel continuous phase to stabilize the water droplets phase and consequently stabilize the emulsion. If the concentration of emulsified agent materials is reasonably high, the merging of water droplets will be prevented [8-9].

Muzio et al. [10] reported that the formation of $\mathrm{NO}_{\mathrm{x}}$ is due to the presence of nitrogen within the diesel fuel, excess oxygen, and high temperature of the combustion gas. On the other hand, if water is added into the diesel fuel in the form of W/D emulsion, the W/D emulsion fuel produces less $\mathrm{NO}_{\mathrm{x}}$ emission than the non-emulsion diesel fuel. According to Lin et al. [11], the W/D emulsion with $20 \%$ water reduced $\mathrm{NO}_{\mathrm{x}}$ emission by $56.8 \%$. During the combustion process of W/D emulsion, the W/D emulsion is sprayed into numerous liquid droplets through a nozzle. Due to the water boiling point is less than that of diesel fuel, the water enveloped layer explodes through the outer oil layer. As a result of microexplosion behavior, the atomized emulsion drops are further atomized into much finer droplets. This mechanism of microexplosion leads to a stronger mixing and a faster rate of reaction between the atomized fuel droplets and the surrounding air [11]. Therefore, a higher extent of combustion is completed. In addition the emission of $\mathrm{NO}_{\mathrm{x}}$, particulate matters, and smoke are significantly reduced [1217]. The addition of water to the diesel to form the emulsion, however, increases the kinematic viscosity of the emulsion as in Figure 1. As can be concluded from Figure which shows the dependency of fuel viscosity on temperature. At temperature $40^{\circ} \mathrm{C}$, the viscosity of diesel fuel is about $4 \mathrm{cSt}$, where it is about $43 \mathrm{cSt}$ for the $30 \% \mathrm{~W} / \mathrm{D}$ emulsion. This is not desirable to the engine injection systems, nor the performance and emissions of hydrocarbons. Therefore it may be necessary to reduce the viscosity of the emulsion to enable its utilization in diesel engines with no injection systems short term and long term complications and to avoid the combustion irregularities and increased exhaust emissions of other gasses.

Therefore, it is the objective of the current study to investigate the effects of adding very low viscosity additive; which is renewable in nature, on the water-in-diesel stabilized emulsions with different concentrations of the additive over the range of 0 to $20 \%$ in $5 \%$ increments. That additive is selected to be Di-Ethyl-Ether which has very low viscosity and it is renewable or derived from renewable sources. The 30\% water-in-diesel emulsion has been mixed with DEE with different concentrations and used in the diesel engine with no modifications. The DEE has been used before to study its effects on the exhaust emissions and ignition delay period of diesel engine [18].

The engine combustion pressure and other performance parameters have been recorded, and the pressure rise rate has been calculated from the offline data and the maximum pressure rise rate at different operating conditions has been picked along with the combustion pressure at each condition to represent the engine roughness and combustion noise. The maximum combustion pressure and the maximum pressure rise rate have been presented for different engine operating conditions of speed, load or fuel injection timing, for $30 \%$ W/D emulsion with different concentration of DEE.

\section{Experimental Work}

\subsection{Emulsions Preparation}

Diesel fuel from ADNOC-United Arab Emirates was used in the preparation of stable W/D emulsion and consequently in the investigation of the prepared samples. Table 1 shows the physical properties of the employed regular diesel fuel. The compositions of the used diesel fuel by weight are $87.2 \%$ carbon, $12.8 \%$ hydrogen. The diesel fuel contains $0.0225 \%$ sulphur and an aromatic content of $29.3 \% \quad(13 \%$ monoaromatics, $13.3 \%$ diaromatics and $3 \%$ polyaromatics).

Table 1. Fuels Properties.

\begin{tabular}{lll}
\hline Fuel Propriety & Diesel Fuel & Di-Ethyl-Ether \\
\hline Chemical Formula & Hydrocarbons $\sim \mathrm{C} 10-\sim \mathrm{C} 21$ & $\mathrm{C}_{2} \mathrm{H}_{5} \mathrm{OC}_{2} \mathrm{H}_{5}$ \\
Boiling point, C & $180-360$ & 35 \\
Latent heat of vaporization, $\mathrm{kJ} / \mathrm{kg}$ & 233 & 356 \\
Cetane number & $40-55$ & $>125$ \\
Auto-ignition temperature, C & 315 & 160 \\
Density, $\mathrm{kg} / \mathrm{m}^{3}$, at $15 \mathrm{C}$ & 860 & 714 \\
Lower Heating Value, $\mathrm{MJ} / \mathrm{kg}$ & 42 & 33.9 \\
Stoichiometric air-fuel ratio, $\mathrm{kg} / \mathrm{kg}$ & $14-14.7$ & 11.2 \\
Viscosity, C.P. (mm2/sec) at $40 \mathrm{C}$ & $2.6-4.1$ & 0.23 \\
Oxygen content $($ by $\% \mathrm{Wt}$ ) & 0 & 21 \\
\hline
\end{tabular}

In general, Water-in-oil emulsion can be prepared by mixing the two immiscible fluids in the presence of a surface active material. The mixing system produces very small water droplets phase dispersed within the oil continuous phase. The emulsifying agent added to the mixture reduces the interfacial tension between the water and the oil, which is 
necessary to form the emulsion and to stabilize the water droplets phase within the continuous oil phase. Stable waterin-diesel emulsion was prepared by gradual addition of certain amount of water into the diesel fuel phase that contains $0.2 \%$ by volume of surfactant agent while a high speed mixer was in rotation. A non-ionic surfactant, Triton X100 (from BDH Middle East L.L.C.-United Arab Emirates), was used as an emulsifying agent. $30 \%$ water was added to prepare stable $30 \% \mathrm{~W} / \mathrm{D}$ emulsion. Different mixing speeds for different mixing times were examined to prepare stable W/D emulsions. The prepared samples of emulsion were placed into graduated glass cone-containers to check the stability of the sample. The main criterion for the stable emulsion is the presence of only one phase. If more than one layer is found, it must be considered as unstable emulsion. It is necessary to find the experimental conditions required to maintain the $30 \% \mathrm{~W} / \mathrm{D}$ emulsion in stable status for a reasonable period of time to cover the different stages of the experimental measurements. Experimentally, it has been found that $5000 \mathrm{rpm}$ for six minutes of mixing time was sufficient to prepare stable $30 \% \mathrm{~W} / \mathrm{D}$ emulsion. All the experimental measurements were carried out at room temperature of $25^{\circ} \mathrm{C}$. The temperature was controlled through a thermostat circulating bath.

\subsection{Experimental Setup}

A Ricardo E6 research engine is used in the test setup which is a single cylinder compression ignition engine. The engine is fully equipped with instrumentations for measurements of all engine operating parameters. It is important to emphasize that there were no modifications needed on the engine to work with emulsified fuels. The engine is loaded by an electrical dynamometer rated at $22 \mathrm{~kW}$ and $420 \mathrm{~V}$. The torque of the engine is measured through force transducer that is connected to the electrical dynamometer which has uncertainty of $\pm 0.1 \mathrm{~N}$. The liquid fuel flow rate is calculated by measuring the time needed to consume fix amount of the liquid fuel. The engine specifications are shown in Table 2.

Table 2. Ricardo E6 Engine specifications.

\begin{tabular}{ll}
\hline Engine type & Variable compression research engine Ricardo E6 \\
\hline Number of cylinders & 1 \\
Bore & $76.2 \mathrm{~mm}$ \\
Stroke & $111.1 \mathrm{~mm}$ \\
Swept Volume & 0.607 liters \\
Max. Speed & $60 \mathrm{rev} / \mathrm{sec}(3000 \mathrm{rpm})$ \\
Max. Power, Diesel $(\mathrm{CR}=20.93)$ & $9.0 \mathrm{~kW}$, Naturally Aspirated \\
Compression Ratio (CR) & Max. CR 22 \\
Injection Timing & Variable, $20^{\circ}-46^{\circ} \mathrm{btdc}$ \\
\hline
\end{tabular}

The flow rate of air is measured using a calibrated orifice meter with pressure transducer arrangement. The pressure transducer has uncertainty of $\pm 0.1 \mathrm{~Pa}$. The liquid fuel flow rate is measured by recording the required time to consume a fixed volume of liquid with uncertainty of $\pm 0.1 \mathrm{ml} / \mathrm{s}$. The measurement of combustion pressure, engine speed, engine output torque, and crank angle are collected using a high speed data acquisition system. A LAB VIEW interface program has been written to collect the data at a rate of 60,000 points per second and to store the data.

The main objective of the conducted experiments is to understand the effect of adding the DEE as an additive to the $30 \% \mathrm{~W} / \mathrm{D}$ emulsion. To fully understand the effect of adding the additive on the performance of a single cylinder CI engine, numerous tests are conducted under different conditions as listed below:

(a) Tests under different engine injection timing of the liquid fuel, and this is varied from 20 to 45 degrees BTDC. This experiment has been carried out at constant engine speed of $1200 \mathrm{rpm}$ and compression ratio of 22 .

(b) Tests under different loading conditions where the engine speed has been kept constant at $1200 \mathrm{rpm}$ and the injection timing kept at 35 degrees BTDC and compression ratio kept at 22 .

(c) Tests under different engine speeds, where the engine injection timing has been kept at 35 degrees BTDC and compression ratio kept at 22 .

\section{Results and Discussion}

The effect of DEE additive enrichment on CI engine performance running on $30 \% \mathrm{~W} / \mathrm{D}$ emulsified fuel is addressed in the current study in terms of combustion pressure and maximum combustion pressure rise rate.

Figure 2 illustrates the effect of the engine injection timing on the maximum combustion pressure for pure diesel fuel and $30 \% \mathrm{~W} / \mathrm{D}$ emulsion. All other conditions of engine speed and compression ratio are constant. It can be concluded from Figure 2 that the earlier fuel injection towards 45 degrees for instance, increases the combustion pressure. The earlier injecting in relatively cooler air environment increases the delay period and the fuel takes more time to ignite, where more amount of fuel is injected, and therefore self-ignition of that increased amount leads to higher pressure.

When water is added to the diesel, the emulsion would need more time to ignite at a higher rate; as shown in Figure 3 , and the pressure increased as displayed in the figure. When the Di-Ethyl-Ether is added to the emulsion at 5\%, however, the maximum combustion first increased to higher values than the pure emulsion without the DEE. This may be seen in Figure 4 (versus the speed), Figure 5 (versus the injection time) and Figure 6 (versus the load). The increase in the maximum combustion pressure when $5 \%$ of DEE is added may be attributed to some of the physical and chemical 
properties (Table 1) such as the higher Cetane number than diesel, lower ignition temperature, and the increased content of available Oxygen in the fuel. This may have helped the mixture to ignite more rapidly with less ignition delay period and increase the combustion pressure during the compressions stroke well ahead the top dead center. However, when the DEE is increased to higher ratios of 10$20 \%$ as shown in the same three Figures, other properties become more dominant, e.g. the lower heating value than diesel and higher latent heat of vaporization than diesel. The reduced heating value of DEE decreases the overall heating value of the mixture of diesel-DEE and hence less heat is available for release and the maximum pressure gradually decline. Furthermore, due to the addition of DEE with higher latent heat of vaporization, the DEE would absorb more heat from the mixture to evaporate which tends to reduce the overall temperature before ignition and therefore increase the delay period and eventually lower the temperatures and pressures inside the cylinder. This result in agreement to the previous work of ignition delay period measurement for such mixture [18]. Decreasing or increasing the maximum combustion pressures would affect the net-work output from the engine and hence the power and torque produced. Even if the pressures are not changed, when adding DEE, but the reduced kinematic viscosity of the mixture would improve the engine injection system durability and long term use.

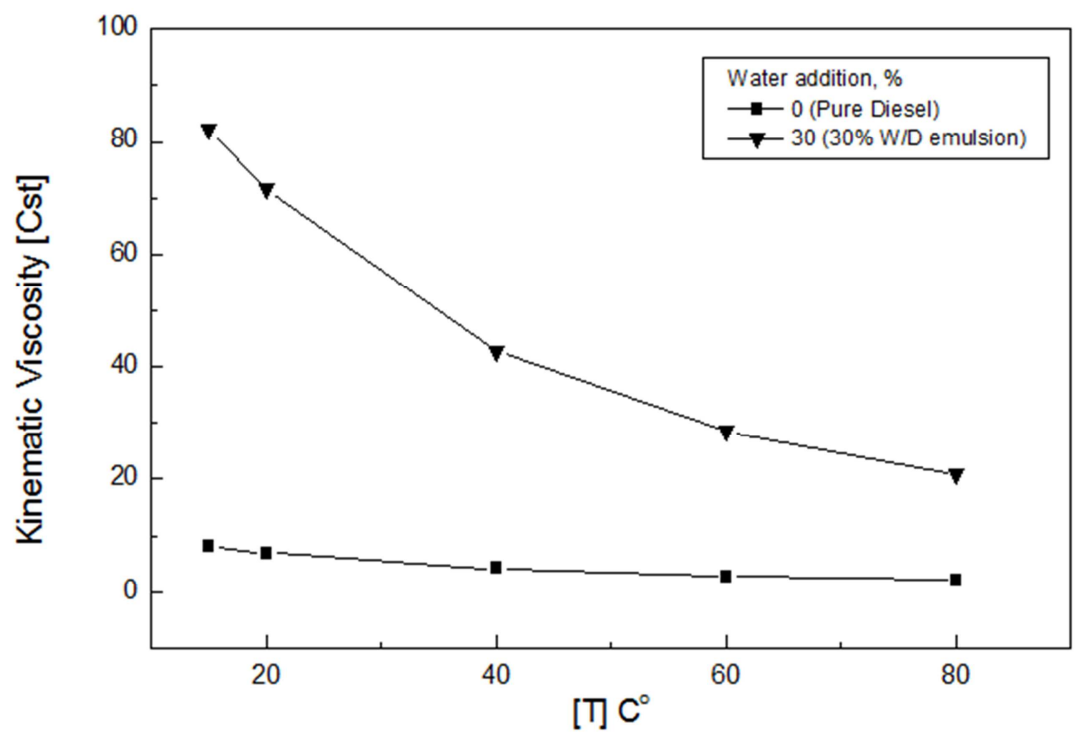

Figure 1. Kinematics viscosity of pure diesel fuel and 30\% W/D emulsion with temperatures.

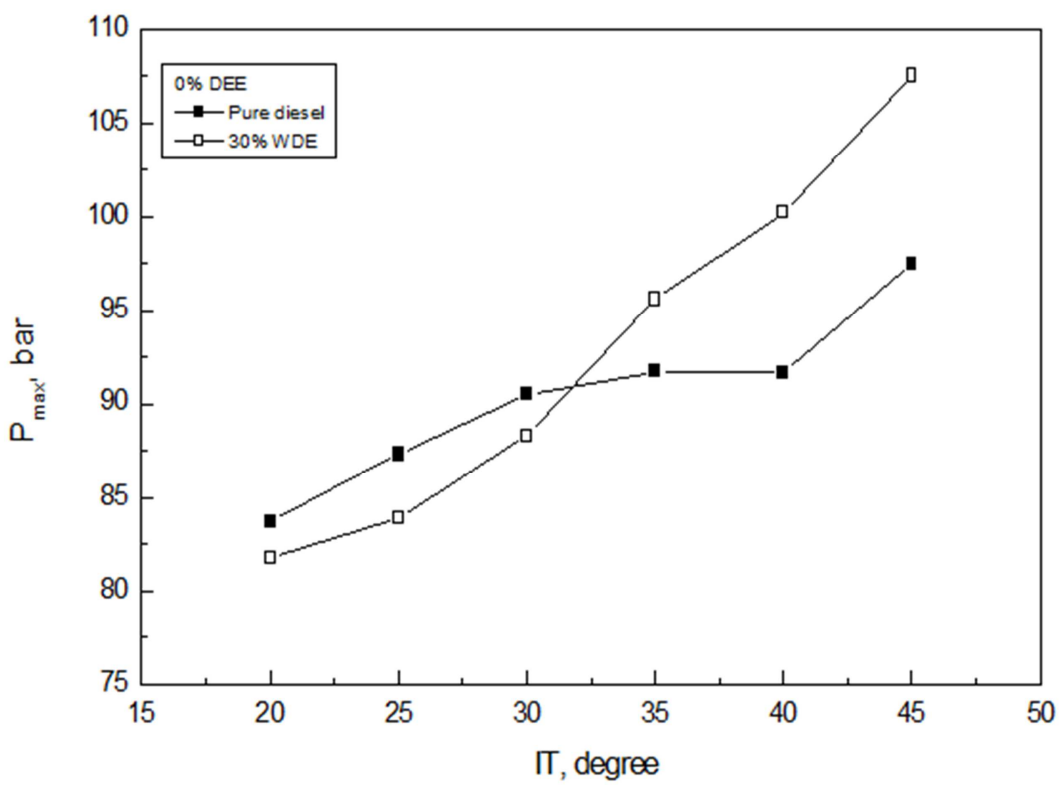

Figure 2. Maximum combustion pressure with injection timing for diesel fuel and 30\% W/D emulsion. 


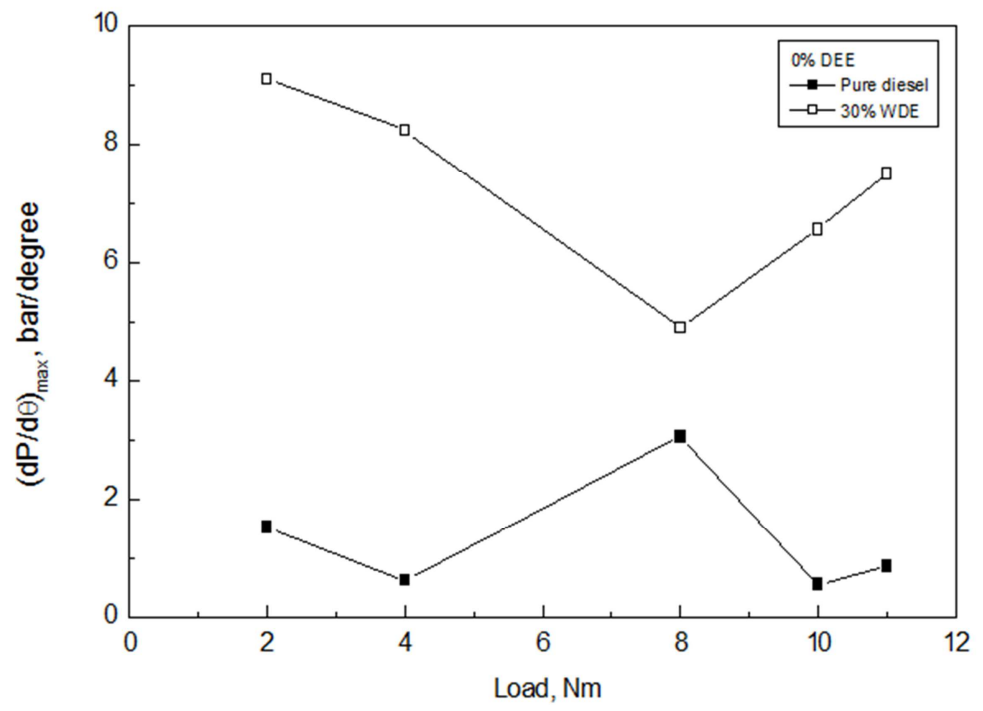

Figure 3. Maximum pressure rise rate with engine load for diesel and diesel-30\% water emulsion.

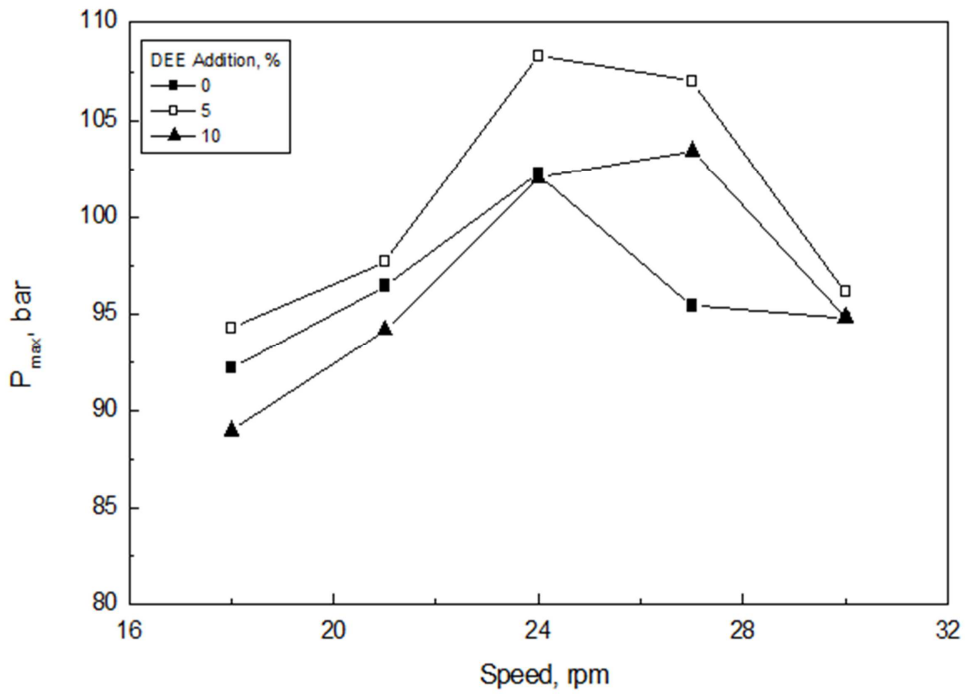

Figure 4. Maximum combustion pressure with engine speed for diesel-30\%water emulsion at different Di-Ethyl-Ether (DEE) percentages.

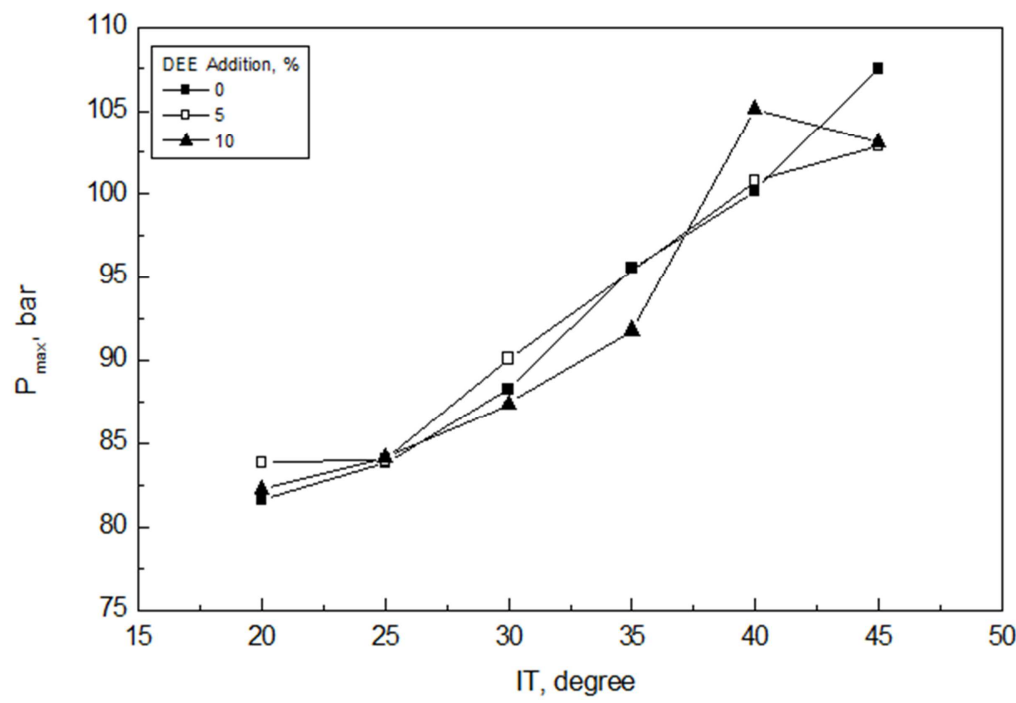

Figure 5. Maximum combustion pressure with engine injection timing for diesel 30\% water emulsion at different Di-Ethyl-Ether (DEE) percentages. 


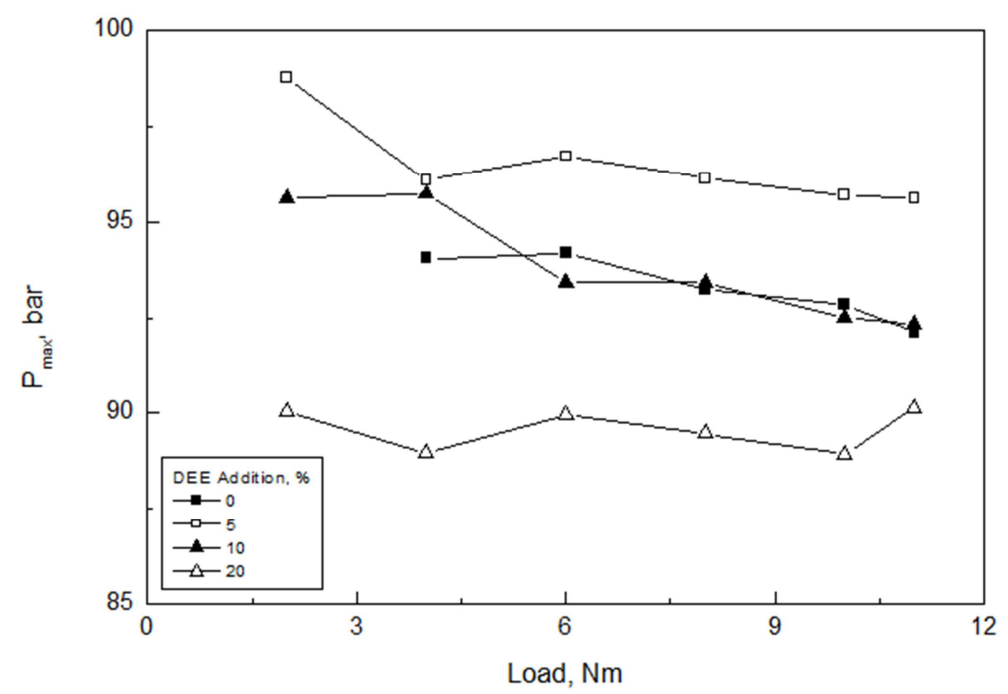

Figure 6. Maximum combustion pressure with engine load for diesel-30\%water emulsion at different Di-Ethyl-Ether (DEE) percentages.

\section{Conclusions}

The effect of Di-Ethyl-Ether addition on the combustion characteristics of $30 \%$ water-diesel emulsion fuel and its viscosity was investigated. It has been found that the presence of water in the W/D emulsion resulted in the increase of its kinematic viscosity. To decrease the viscosity, a low viscosity chemical; DEE; was added which resulted in a reduction in the kinematic viscosity of the $30 \%$ waterdiesel emulsion. The diesel engine can efficiently run smoothly with $30 \%$ water in diesel emulsion without any engine modifications.

The addition of water into the diesel fuel increases the maximum pressures in the cylinder especially when early injection timing is used. This is due to the increased pressure rise rate for the emulsion. The addition of 5\% of Di-EthylEther to the $30 \% \mathrm{~W} / \mathrm{D}$ emulsion increases the maximum combustion pressures, however, adding more DEE decreases the maximum combustion pressure.

The addition of DEE generally improves the properties of the water-diesel emulsion and affects the combustion pressures and pressure rise rate. The addition of water to diesel would reduce the dangerous emissions of Nitrogen Oxides, however, this may be tolerated with some increase in the engine pressure rise rate.

\section{References}

[1] Lin, C.; Pan, J. Corrosion Characteristics of Furnaces Burning with Emulsified Diesel Oil Contained Sodium Sulfate. Corros Prev Control 2001, 47 (3): 83.

[2] Nicholls, J.; El-Messiri, I.; Newhall, H. Inlet Manifold Water Injection for Control of Nitrogen Oxides-Theory and Experiment. SAE paper number 690018, 1969.

[3] Lestz, S.; Melton, R.; Rambi, E. Feasibility of Cooling Diesel Engines by Introducing Water Into the Combustion Chamber. SAE paper number 750129, 1975.
[4] Andrews, G.; Bartle, K.; Pang, S.; Nurein, A.; Williams, P. The Reduction in Diesel Particulate Emissions Using Emulsified Fuels. SAE paper number 880348, 1988.

[5] Mingyuan, L.; Christy, A.; Sjoblom, J. In: Sjoblom Ed. Emulsions-a Fundamental and Practical Approach; Kluwer Academic Publishers: Dordrecht, V363, 1992.

[6] Pilehvari, A.; Saadevandi, B.; Halvaci, M.; Clark, D. In: Roco MC Ed. Pipeline Transportation of Heavy Crude as Emulsions. Proc. $3^{\text {rd }}$ Int. Symp. Liquid Solid Flows; ASME V75: New York, 1988.

[7] Sherman, P. In: Becher Ed. Encyclopedia of Emulsion Technology; Dekker: New York, 1983.

[8] Bobra, M. In: Proceeding of Arctic and Marine Oil Spill Program; Environmental Canada - Minister of Supply and Services: Ottawa, 1990.

[9] Eley, D.; Hey, M.; Symonds, J.; Willison, J. Electron Micrograph of Emulsions of Water in Crude Petroleum. $J$ Colloid Int Sci 1976, 54: 462.

[10] Muzio, L.; Quartucy, G. Implementing $\mathrm{NO}_{\mathrm{x}}$ Control: Research to Application. Prog. Energy Combustion Sci. 1997, 23 (3), 233.

[11] Lin, C.; Wang, K. Diesel Engine Performance and Emission Characteristics Using Three-Phase Emulsions as Fuel. Fuel 2004, 83, 537.

[12] Adiga, K.; Shah, D. On the Vaporization Behavior of water-inOil Microemulsions. Combust Flame 1990, 80, 412.

[13] Wang, C. Law C. Microexplosion of droplets Under High Pressure. Combust Flame 1985, 59, 53.

[14] Crookes, R.; Kiannejad, F.; Nazha, M. Systematic Assessment of Combustion Characteristics of Biofuels and Emulsions with Water for Use as Diesel Engine Fuels. Energy Convers Manage 1997, 38, 1785.

[15] Crookes, R.; Kiannejad, F.; Nazha, M. Seed Oil Biofuel of Low Cetane Number: The Effect of Water Emulsification on Diesel Engine Operation and Emissions. J Inst Energy 1995, 68,142 . 
[16] Crookes, R.; Nazha, M.; Kiannejad, F. Single and MultiCylinder Diesel Engine Tests with Vegetable Oil Emulsions. SAE paper number $922230,1992$.

[17] Sheng, H.; Chen, L.; Wu, C. The Drolet Group MicroExplosions in W/O Diesel Fuel emulsion Sprays. SAE paper number $950855,1995$.
[18] Subramanian, K. and Ramesh, A., "Use of Diethyl Ether Along with Water-Diesel Emulsion in a Di Diesel Engine," SAE Technical Paper 2002-01-2720, doi:10.4271/2002-01$2720,2002$. 